\title{
"É ajuda, não é prostituição". Sexualidade, envelhecimento e afeto entre pessoas com condutas homossexuais no Pantanal de Mato Grosso do Sul*
}

\author{
Guilherme Passamani**
}

\section{Resumo}

Este artigo é parte de uma pesquisa maior que problematizou a intersecção entre envelhecimento, memória $e$ condutas homossexuais na região do Pantanal de Mato Grosso do Sul. Discutirei aqui as mudanças e perspectivas operadas ao longo do curso da vida de alguns de meus interlocutores no universo da sexualidade e do envelhecimento. Analisarei a categoria ajuda para perceber as estratégias que são construídas para estabelecer vínculos afetivos, eróticos e sexuais. Por último, destacarei as relações entre sexo, afeto, erotismo e dinheiro entre os interlocutores, seus amantes e a prostituição.

Palavras-chave: Sexualidade, Envelhecimento, Ajuda, Condutas Homossexuais, Prostituição.

* Recebido em 11 de dezembro de 2015, recebido em 07 de agosto de 2017.

*** Professor do Programa de Pós-Graduação em Antropologia Social, Faculdade de Ciências Humanas, Universidade Federal de Mato Grosso de Sul, Campo Grande, MS, Brasil. grpassamani@gmail.com 


\author{
"It Is Help, Not Prostitution". Sexuality, Aging and Affection \\ Among Persons with Homosexual Conduct in The Pantanal of \\ Mato Grosso do Sul
}

\begin{abstract}
This article integrates a broader research worried with the intersection among aging, memory and homosexual conducts in Pantanal region of Mato Grosso do Sul. I discuss here the changes and perspectives operated during the life course of some of interlocutors of mine in what concerns sexuality and aging. I analyze help as a category to understand the strategies used to establish emotional, erotic and sexual bonds. Finally, I mark the relations among sex, affection, erotism and money among the interlocutors, their lovers and prostitution.
\end{abstract}

Keywords: Sexuality, Aginghelp, Homosexual Conducts, Prostitution. 


\section{Introdução}

A investigação ${ }^{1}$ que resulta neste artigo problematizou a intersecção entre envelhecimento, memória $e$ condutas homossexuais ${ }^{2}$ na região do Pantanal de Mato Grosso do Sul, nas cidades de Corumbá (108 mil habitantes) e Ladário (21 mil habitantes), nas cercanias da fronteira com a Bolívia.

O Pantanal é considerado uma das maiores extensões úmidas contínuas do planeta. São $138.183 \mathrm{~km}^{2}$ que ocupam o centro da América do Sul, no Brasil e na Bolívia. No que diz respeito à fronteira, foi somente ao final da guerra contra o Paraguai, que ela foi consolidada, possibilitando sua posterior ocupação e colonização de forma mais efetiva (Corrêa e Corrêa, 2013).

1 Pesquisa de doutorado em Ciências Sociais, defendida em setembro de 2015, no Instituto de Filosofia e Ciências Humanas da Unicamp, na linha de Estudos de Gênero, sob orientação da Profa. Dra. Guita Grin Debert. Durante o trabalho de campo, realizado entre julho de 2012 e fevereiro de 2014, buscou-se estabelecer contato com uma gama variada de pessoas com condutas homossexuais, maiores de 50 anos, residentes nas duas cidades para pensar trajetórias, curso da vida e possíveis idiossincrasias que poderiam existir na experiência desses sujeitos em regiões que não são caracterizadas como grandes centros urbanos.

2 Utilizo a expressão "condutas homossexuais" para me referir aos sujeitos com os quais eu estou trabalhando. É apenas um recurso para tentar aproximar uma série de categorias muito dispersas entre si e tratá-las em seus próprios termos. Utilizo esse recurso por estar lidando com informações acionadas por meio da memória e que falam, algumas vezes, de tempos que não são o presente; e o que me é contado carrega uma fluidez grande entre o que atualmente compreendemos como orientação sexual e identidade de gênero. Ao falar em condutas homossexuais, estou fazendo uma referência às pesquisas de John Gagnon (2006). Para ele, as condutas sexuais seriam atos que exigiriam desenvolvimento da criatividade, amparadas por aspectos culturais mais amplos, fantasias individuais e códigos que permitiriam algum grau de interação social. Segundo Gagnon, a partir de sua crítica à "natureza" social dos comportamentos humanos, ele conseguiu explicar a importância e relevância da discussão sobre condutas sexuais. A explicação de Gagnon seguia o seguinte raciocínio: se todo o comportamento humano é social, não há possibilidade de existir um comportamento sexual biologicamente nu, mas sim uma conduta sexual socialmente vestida. 
Trata-se, desse modo, de um "interior" de fronteira, de cruzamentos e também de passagem, porque as pessoas vão quase sempre para lá em razão de trabalho ou turismo. ${ }^{3}$ Como as cheias do Pantanal, há períodos de marcado refluxo populacional, em que, outra vez, Corumbá exibe os traços de cidade provinciana ${ }^{4}$, onde, como dizem alguns de meus interlocutores, a rede de relações pessoais é bem estreita, o que dá margem à fofoca e exige mediações do segredo para algumas instâncias da vida social. De todo modo, nesse cenário há muita circulação $e$ "inchaços" pontuais, como na época das festas.

Hoje, Corumbá conta com pouco mais de 108 mil habitantes e tem sua economia fortemente ligada à exploração de minérios (o calcário, por exemplo), à pecuária, ao turismo, ao comércio e aos serviços de maneira geral. Ainda assim, a cidade é muito pobre e socialmente desigual. Há visivel discrepância entre ricos e pobres, entre aqueles que moram antes dos trilhos do trem, mais próximos ao centro da cidade e à região conhecida como Porto Geral, e a parcela majoritária da população, que mora depois dos trilhos, nos bairros mais pobres e periféricos, seja no que diz respeito à infraestrutura, acesso a bens de consumo, entretenimento e mobilidade urbana. A pobreza $e$ a distância das grandes metrópoles ajudam a compor o mosaico de particularidades que fazem ser muito específica a experiência do envelhecimento entre sujeitos com condutas homossexuais na região do Pantanal.

3 Corumbá, por exemplo, é reconhecida em Mato Grosso do Sul como uma "cidade alegre" e festiva. Essa referência foi conquistada a partir das diversas festas, como o carnaval e as dos santos populares, mas também devido aos festivais culturais, musicais, além do turismo ecológico, sem contar o fato de ser rota para o turismo rumo aos Andes peruanos. Agradeço ao professor $e$ pesquisador Tiago Duque, que faz campo na região, as reiteradas conversas que tivemos a esse respeito.

${ }^{4}$ Usarei itálico nas falas e expressões dos interlocutores, bem como para palavras estrangeiras; $e$ aspas para conceitos de autores ou expressões explicativas utilizadas por mim. 
Outra característica importante da região é a presença do Sexto Distrito Naval da Marinha do Brasil, instalado na cidade de Ladário. ${ }^{5} \mathrm{O}$ imaginário do lugar é influenciado pela presença dos marinheiros e as relações sociais foram sendo alteradas à medida que os diferentes sujeitos que compóem a Armada começaram a entrar em contato com os moradores locais. Corumbá e Ladário são cidades que ocupam posições estratégicas do ponto de vista geopolítico, pois estão na fronteira com a Bolívia. Além disso, há ali contingentes permanentes das Forças Armadas (Marinha $e$ Exército), fazendo com que sejam cidades de desterritorializações. Nelas, há um fluxo de homens, de corpos masculinos desterritorializados. ${ }^{6}$ Esse pode ser mais um fator a particularizar a experiência das pessoas com conduta homossexual na região.

Há toda uma literatura que se empenha em mostrar como os sujeitos homossexuais parecem conseguir se realizar enquanto sujeitos apenas a partir de um processo de migração que teria como tônica a questão da orientação sexual. ${ }^{7}$ Em relação à pesquisa que deu origem a este artigo, o fato a ser destacado é justamente a possibilidade aberta pela pesquisa de abordar as condutas homossexuais de sujeitos que não migraram, ou seja, que, em espaços aparentemente e a priori adversos, construíram vivências possíveis e desenvolveram estratégias de gestão da visibilidade para suas condutas. Nesse sentido, ocupei-me de sujeitos que parecem estar na contramão do clássico processo de migração para grandes centros com vista à realização plena de sua

\footnotetext{
${ }^{5}$ Ladário é hoje uma cidade de pouco mais de 20 mil habitantes. De maneira geral, pensa-se Ladário como uma continuação de Corumbá. Embora a Marinha já estivesse presente na região do Pantanal desde 1827, com o Arsenal de Cuiabá, ela chegou, oficialmente, a Ladário em 07 de janeiro de 1873, primeiro como um Arsenal Naval e, ao longo do século XX, transformando-se no Sexto Distrito Naval.

${ }^{6}$ Sobre desterritorialização, ver Castells (2000).

7 Sobre o processo migratório de pessoas com conduta homossexual, são importantes referências as obras de Kath Weston (1995) e Andrew GormanMurray (2007) no cenário estadunidense.
} 
sexualidade, conforme descrito por inúmeros autores (Green, 2000; Guimarães, 2004; Eribon, 2008).

No Brasil, trabalhos como os de James Green (2000), Carmen Dora Guimarães (2004), João Silvério Trevisan (2000), entre outros, apontam claramente para uma suposta necessidade da migração. Nesse sentido, como trabalhos importantes $e$ pioneiros que foram, produziu-se, a partir deles (com influência de uma produção internacional que também caminhava nesse sentido) uma série de leituras que colocou, quase como questão obrigatória, o processo migratório desses sujeitos das cidades menores para as capitais. Os meus dois primeiros trabalhos apontaram também nesse sentido, devedores dessas leituras pioneiras da produção brasileira. Eles repetiam uma máxima que ouvia já nos tempos de minha primeira pesquisa na cidade de Santa Maria, no interior do Rio Grande do Sul: "bicha só é bicha na capital'.

A aproximação com meus interlocutores se deu de formas variadas e envolveu: contatos estabelecidos com ONGs da cidade que, por meio de suas redes, levaram-me até alguns interlocutores; contatos estabelecidos com pessoas ligadas à Universidade Federal do Mato Grosso do Sul, campus do Pantanal, que me possibilitaram contatar sujeitos ligados ao universo do carnaval; $e$ também por meio de contatos em salas de bate-papo na internet.

Discutirei neste artigo, em um primeiro momento, as mudanças e perspectivas operadas, ao longo do curso da vida de alguns de meus interlocutores, no que diz respeito ao universo da sexualidade e do processo de envelhecimento. Logo em seguida, procuro analisar algumas categorias, entre elas a ajuda, para perceber as estratégias que são construídas para estabelecer vínculos afetivos, eróticos e sexuais em momentos mais avançados do curso da vida. Por último, procuro destacar as intrincadas relações entre sexo, afeto, erotismo e dinheiro entre meus interlocutores, seus amantes, e o que pode ser percebido como prostituição. 


\section{Sexualidade e envelhecimento: mudanças e perspectivas no curso da vida}

A sexualidade na velhice, no final do século $\mathrm{XX}$, começou a ganhar maior destaque, talvez, em virtude do aumento da expectativa de vida da população em diversos países do mundo, bem como do interesse na criação de um mercado de bens $e$ serviços empenhado em transformar o envelhecimento numa experiência mais gratificante. Tal fato, igualmente, teve lugar no Brasil, onde a visibilidade das pessoas mais velhas é uma crescente. Sendo assim, saberes começaram a ser mobilizados para olhar com maior atenção para os desejos e o erotismo nesse momento da vida.

Como apontam Debert e Brigeiro (2013), a ideia de "envelhecimento ativo" é o modelo mais em voga quando se trata de gestão do envelhecimento no mundo atual. Diante dessa tentativa da Gerontologia de positivação desse momento da vida, a sexualidade se encontra em um lugar central. Manter uma sexualidade ativa ao vivenciar instantes mais avançados do curso da vida representaria, de forma indelével, a vitória de um "envelhecimento ativo".

Essa tentativa da Gerontologia contemporânea faz frente a uma perspectiva que encararia a velhice e o próprio processo de envelhecimento como momentos em que se viveria uma "maturidade pós-sexual" (Debert; Brigeiro, 2012), em que a sexualidade deveria ser deserotizada (Katz; Marshall, 2003). As mudanças diante dessa Gerontologia mais tradicional é que levaram à inclusão e à defesa da sexualidade no curso da vida, especialmente, na velhice:

O panorama atual configura-se como diferente: a inclusão da velhice no curso da vida sexual é o imperativo que marca a reflexão dos especialistas sobre o tema, o que acontece em consonância com as tendências teóricas vigentes no campo gerontológico nas últimas décadas. Uma velhice sexualmente ativa vem se estabelecendo como um ideal defendido por gerontólogos e outros especialistas afins 
ao tema, e é intensamente propagado pelos meios de comunicação de massa (Debert, Brigeiro, 2012:31).

Ricardo lacub (2002), por exemplo, diz que o erotismo na velhice é recoberto ora por um silêncio, ora por um discurso que o oculta, ainda que percebendo a sua existência. É como se a vida fosse sendo deserotizada à medida que as pessoas fossem ficando velhas. Nesse processo, o prazer sensual transformar-se-ia em ternura e carinho.

No entanto, do ponto de vista de uma "pós-gerontologia", isto é, por meio de uma problematização da Gerontologia desde a leitura pós-moderna e pós-estruturalista (lacub, 2011), estão sendo realizados diversos estudos políticos, culturais e éticos sobre o envelhecimento que funcionam como marcos para pensar, inclusive, sobre o erotismo e a sexualidade nesse momento da vida.

Por isso, tal como Featherstone (1998), talvez seja profícuo pensar o erotismo na velhice, como vem sendo feito pela pósgerontologia, como uma infinita variedade de formas baseadas em uma constante invenção, elaboração, domesticação e regulação do impulso sexual, prolongando as possibilidades de uma sexualidade ativa em momentos mais avançados da vida. Esse é o contexto em que aparecem os "bioejos", que são, justamente, esses velhos biomedicalizados em todos os aspectos fundamentais da vida (Iacub, 2011).

Entretanto, meus interlocutores, de maneira geral, apresentam o momento presente, em que são sujeitos mais velhos, como um tempo de maior calmaria. Isso ocorre, se é possível fazer uma generalização, basicamente, a partir de duas frentes: por um lado, porque há uma limitação física que impede o ritmo de badalação próprio de tempos passados; por outro, a permanente proximidade com a família de origem que, às vezes, envolve, nesse momento da vida o retorno à coabitação. Esses fatos fariam com que os interlocutores se afastassem das práticas sexuais $e$ adotassem uma postura mais caseira e, quem sabe, resignada 
também em função dos contextos de doença que passariam a ser comuns para alguns deles.

É necessária uma crítica à ideia de "envelhecimento ativo", pois ela é uma proposta da Gerontologia atual que, muitas vezes, não encontra eco entre as pessoas mais velhas e pode tornar-se, inclusive, um discurso bastante opressor para todos aqueles sujeitos que não conseguem desfrutar da sexualidade na velhice. Há de se pensar também a validade universalizante de um modelo como esse que pode ser ineficiente diante da multiplicidade de contextos em que estão os sujeitos olhados por diferentes investigações.

Barbosa (78 anos), que é negro, pertencente às camadas populares e sofre de diversas moléstias, diz que a vida do passado acabou. A diferença do passado em relação ao presente seria marcada, entre outros fatores, pelo fato de no passado chover bofe. O interlocutor diz que hoje em dia, todas estão sossegadas. Barbosa é um exemplo de como as duas perspectivas podem aproximar-se, isto é, considera-se sossegado em relação à sexualidade em vista de estar mais velho, ao mesmo tempo em que reside próximo aos parentes e tem um cotidiano marcado por enfermidades que exigem dele não apenas uma rotina de cuidados, mas visitas frequentes ao hospital, o que consome boa parte de seu tempo. E talvez também signifiquem a ausência de uma vida sexual e do prazer erótico.

Talvez uma das conversas mais esclarecedoras sobre a sexualidade nesse momento da vida, quando os interlocutores já estão mais velhos, eu tenha tido com Mauro (67 anos), que é branco e pertencente às camadas médias. $\mathrm{O}$ trecho a seguir sintetiza sua atual visão sobre a sexualidade:

Eu tenho os mesmos desejos, a minha cabeça voa. Eu continuo muito sexual, na cabeça, porque o corpo já dá sinais de que as coisas não andam no mesmo ritmo. Por isso que te digo, minha vida é mais tranquila. Virei caseiro, coisa que eu nunca fazia até uns anos atrás. Estava sempre na rua, de segunda a segunda. Ia atrás dos garotos, 
conseguia e tinha sexo quase sempre. Vivia para conquistar os garotos (Mauro, 67 anos).

O interlocutor é muito didático, inclusive quando aponta o teor das mudanças: trata-se de um "esgotamento" do corpo, mas não de uma "falência" da cabeça. Quer dizer, os desejos persistem, mas, muitas vezes, o corpo não obedece. Isso o obriga a novas dinâmicas que envolvem uma redescoberta do mundo da casa $e$ a busca por uma, ainda que indesejada, impertinente tranquilidade.

Os trabalhos de Iacub (2011), Simões (2004), Featherstone (1998), Brigeiro (2000) e Weeks (1983) mostram uma queixa quase comum: certo sentimento de desorientação diante do mundo dos desejos, do erótico e das práticas sexuais a partir de um momento $\mathrm{X}$ da vida, em que os sujeitos começam a se sentir mais velhos. Esse tempo, o do sentir-se mais velho, não é um momento tácito, demarcado sobre determinados lindes etários, portanto, apresenta-se de maneira completamente fluida e acomete a cada sujeito, geralmente, em tempos particulares.

É interessante o trabalho de Jeffrey Weeks (1983), no contexto inglês, ao mostrar como existem formas diversas de estabelecer o curso da própria vida, como as identidades são consolidadas a partir de múltiplas influências, como os comportamentos sexuais são historicamente orientados e, portanto, como tudo isso está em constante transformação. Sendo assim, uma ideia de vida plena, inclusive do ponto de vista da sexualidade, não deveria ter fim na velhice, mas - como ocorreria com o próprio curso da vida - diante deste novo momento, ela deveria se reinventar.

Seus interlocutores se sentem constrangidos, perdidos, deslocados no mundo homossexual da época (finais dos anos de 1970), sem as inúmeras restrições a que estavam submetidos quando eram jovens, mas também vivenciando uma fase com mais doenças e com menos sucesso nas conquistas eróticas $e$ sexuais. Segundo eles, isso seria motivado pelo fato de não serem mais jovens em um mundo onde a beleza e a juventude seriam 
questões indissociáveis, próprias de um hedonismo que parecia recorrente no mundo homossexual da época.

Alguns dos meus interlocutores contam que ainda mantêm a sexualidade em dia, mas que hoje ela ocupa um lugar bem diferente em suas vidas. A centralidade da sexualidade na vida de alguns deles, muito comum em épocas passadas, foi sendo suprimida em nome de outras situações que, igualmente, dão-lhes bastante prazer: como encontros com amigos $e$ as atividades sociais variadas. Ademais, referem-se a essa nova dinâmica de suas vidas como resultado de uma fase de maior tranquilidade, pois já teriam aprontado muito na cidade e fora dela.

Além disso, um dos interlocutores, Santiago (61 anos), que é pardo e pertence às camadas médias, diz: "quando passa dos sessenta, meu amigo, tem que dar uma acalmada mesmo". Mesmo assim, refuta de maneira peremptória a pecha de velho e espera nunca chegar a essa condição, pois pretende usar todas as possibilidades para se manter na ativa e retardar esse processo, ainda que "pisando no freio" algumas vezes: "Pisar no freio, tudo bem. Parar, nunca". ${ }^{8}$

Esse cenário, por óbvio, não deve ser pensado de maneira generalizada, porque mesmo entre meus interlocutores há o apontamento de possibilidades de reinvenções das experiências de envelhecimento $e$ velhice, inclusive do ponto de vista da sexualidade e do erotismo. Sobretudo entre os que não se sentem velhos, há uma série de estratégias para permanecer na ativa da paquera, ainda que trabalhando em um ritmo mais lento.

\footnotetext{
8 Alguns trabalhos realizados no Brasil são significativos ao mostrar a ocupação das pessoas de mais idade nesse novo momento do curso da vida. Entre eles, destaco alguns: os programas para a "terceira idade", especialmente, para mulheres, promovidos, entre outros, pelo Serviço Social do Comércio, desde os anos de 1960 (Debert, 1999; Alves, 1999); os bailes da "terceira idade" em que reúnem-se casais mais velhos (Alves, 2004); o movimento dos aposentados, transformando essa categoria em um agente político importante, notadamente, o público masculino (Simões, 2000); ou mesmo a sociabilidade em praças e outros espaços, como shopping centers, por exemplo (Brigeiro, 2000).
} 


\section{A ajuda e seus correlatos: tecendo relações afetivas, eróticas e sexuais}

Para os interlocutores da rede dos homens de quase sessenta (composta por um grupo de amigos com condutas homossexuais com mais de cinquenta e menos de sessenta anos), há uma recorrência: eles permanecem sozinhos. Essa, aparentemente, é uma preocupação que não mereceu muito destaque entre os mais velhos. Os meus interlocutores com mais de 70 anos, em nenhum momento, lamentaram ou sublinharam a necessidade de estar com alguém, vivendo uma relação estável, dando a impressão de que esse não era um projeto geracional exequível para eles. Eles são cuidados por familiares ou pretendem, no futuro, passar a residir em um asilo.

Há em nossa sociedade, conforme afirma Jeffrey Weeks (1983), uma ideologia familiar. Weeks diz isso nos primeiros anos da década de 1980, falando desde a Inglaterra, mas suspeito que possamos (com a devida cautela) refletir a partir dessas informações sobre os dias atuais. Há ainda, entre alguns grupos sociais, a ideia de que uma vida plena e realizada se dá com a constituição de uma família (monogâmica, nuclear e heterossexual).

Para Weeks, a partir de sua investigação, talvez a obrigação com a constituição de uma família tenha feito com que alguns de seus interlocutores ficassem apreensivos a respeito da velhice, justamente porque não se enquadravam no modelo familiar, sobremaneira por, em tese, faltar uma rede de apoio - uma garantia que, porém, a família não garante em sua totalidade. Ter uma família não é, necessariamente, ter uma rede de suporte na velhice. No entanto, o imaginário que povoa o social é o de que sim, a família garantiria uma velhice não solitária e sob cuidados. ${ }^{9}$

Santiago (61 anos), por exemplo, não lamenta o fato de permanecer sozinho. Além disso, diz que essa é uma escolha sua,

9 É bem interessante a discussão final da dissertação de Thiago Soliva (2012) sobre a constituição das famílias de coração, famílias de escolha, famílias afetivas, enfim, aquelas que são estabelecidas a partir de sujeitos que não têm vínculos consanguíneos. 
pois, se quisesse, teria uma relação estável, uma vez que "tenho uns apaixonados por mim. Ficam todo dia me ligando". Por outro lado, se diz completamente desacostumado da possibilidade de constituir uma família com outro homem, já que no passado tivera a experiência de coabitar.

Deco (54 anos), que é branco e pertencente às camadas médias, mostra resistências ao estabelecimento de uma vida a dois, por exemplo, no que diz respeito a constituir uma relação igualitária do ponto de vista da divisão de tarefas. Ele conta que na cidade é comum as pessoas com conduta homossexual se envolverem com homens socialmente reconhecidos como heterossexuais, os quais seriam bancados, pela bicha. Esse seria um tipo de relação que não lhe interessaria hoje. Mas ele vê que muitas pessoas próximas a ele, na tentativa de fugir da solidão, acabam submergindo nesse tipo de relação: "bancar alguém para fugir da sua própria solidão. Furada. Nunca colou comigo".

$\mathrm{O}$ interlocutor sinaliza algumas mudanças no estabelecimento dos encontros afetivos, eróticos e sexuais - que coincidem com a idade mais avançada dos interlocutores - $e$ a partir das quais se torna necessário algum tipo de plus para que as relações não apenas sejam estabelecidas, mas mantidas $e$ desenvolvidas. Nesse momento, Deco chama esse plus de bancar.

Outras categorias são acionadas: a ajuda $^{10}$, o agradar, o incentivo, o presente, entre outros. Todas essas categorias se opõem à ideia de prostituição. A troca de dádivas com os novos amantes envolve o plus que não é visto como prostituição. ${ }^{11}$

10 "Ajuda é uma noção amplamente difundida nas camadas baixas e médias baixas do Brasil. Ela remete a contribuições econômicas que, embora consideradas relevantes, não constituem a principal fonte de recursos para a subsistência (Gregg, 2006). No marco de relacionamentos sexuais e afetivos, a ajuda é frequentemente trocada por sexo, não necessariamente dissociado de afeto. Essas relações, nas leituras locais, não são vistas como prostituição [...]. E se o programa evoca um contrato de serviços, a ajuda, inserta em uma tradição de intercâmbios hierárquicos, remete a noções de amparo, cuidado e afeto que se expressam em termos de contribuição para a sobrevivência econômica" (Piscitelli, 2008:08).

${ }^{11}$ Sobre a "ajuda" no universo da prostituição, ver (2008). 
As estratégias que envolvem a troca de favores sexuais $e$ algum benefício recebem diversas nomenclaturas $e$ acionam diferentes sujeitos que constituem vínculos. ${ }^{12} \mathrm{O}$ que os interlocutores deixam claro é que no estabelecimento das relações mediadas por diferentes níveis de ajuda, há a recorrência do afeto, matizado ora por respeito, consideração e cuidado, categorias que, igualmente, apareceram no trabalho de campo de Piscitelli. ${ }^{13}$

Luma (57 anos), que é parda e pertence às camadas populares, ao argumentar que se sente envelhecendo, diz ter uma vida boa, mas que para ser melhor gostaria de ter um companheiro. Ela diz sentir falta de uma companhia. A interlocutora preferiria um companheiro jovem, o que ela chama de garotão. Não digo dividir contas, estas coisas, mas dividir a vida. A interlocutora sente a falta de uma companhia e gostaria de ter esse companheiro para não necessitar recorrer aos serviços de "garotos de programa", segundo ela, a forma mais comum de se relacionar com homens nos últimos tempos.

A interlocutora, para ter a companhia de um garotão, estaria disposta a pagar integralmente as contas da casa, pois afirma que, com homem ou sem homem, teria que pagá-las do mesmo jeito. Ela conta que com a idade que está, 57 anos, precisa ser realista e encarar os fatos: seria muito difícil um garotão se interessar por ela, principalmente, "em um tempo que esta mulherada, esta meninada que beijou, já tá baixando a calcinha, a troco de quê

\footnotetext{
12 "Esta figura do homem mais velho envolvido com alguém mais novo $e$ trocando dádivas, já foi descrita por Cláudia Fonseca (1996) como o velho que ajuda, em suas pesquisas em Porto Alegre. Naquele contexto, este sujeito servia de uma possibilidade concreta de ascensão social para gurias pobres que queriam melhorar de vida via prostituição. Segundo Piscitelli, este velho que ajuda é um cliente que se torna freguês, fornecendo, além de pagamento regular, um amplo leque de presentes e, eventualmente, uma casa" (2008:09).

${ }^{13}$ Adriana Piscitelli (2008) faz esse debate também levando em consideração os contextos transnacionais. No exterior, então, a categoria ajuda pode ser acionada para conseguir inserir-se no contexto migratório, para deixar a prostituição, para obter empregos, para conseguir alugar imóveis, para ingressar em diferentes níveis de escolarização, ou mesmo casamentos e regularização da situação civil no país estrangeiro etc.
} 
ele vai vir aqui pegar uma cinquentona como eu? Se ele não tiver interesse em alguma coisa?".

A intersecção entre condição socioeconômica e geração parece flagrante aqui. Essa não é uma questão nova e aparece em algumas pesquisas sobre o tema: bicha velha que se envolve com um homem mais pobre e mais novo. No entanto, talvez, a novidade seja um descolamento desse tipo de prática do que habitualmente é nomeado por prostituição.

Mauro (67 anos), que é branco e pertence às camadas médias, conta que conhece seus casos, basicamente, pela internet. Diz-se encantado pelas possibilidades proporcionadas por essa nova tecnologia de comunicação. Os homens com quem se relaciona são da cidade ou de cidades vizinhas, que iriam para Corumbá bancados por ele para o encontro. Algumas outras vezes, contrata "garotos de programa". Mauro diz que ele faz questão de ajudar.

Às vezes, nem cobram, mas eu ajudo de alguma forma. Dou um presente. Levo pra jantar numa espeteria. Coisas assim. Um, uma vez, me pediu uma volta de carro pela cidade. Ele não conhecia a cidade, acredita? Nunca tinha andado de carro. Eu levei ele para passear. Gostei muito (Mauro, 67 anos).

Mauro traça diferenças no estabelecimento de relações que se aproximam e, ao mesmo tempo, se afastam da prostituição. Ele fala que também utiliza o serviço de "garotos de programa", mas que essa não é a forma exclusiva entre as relações que estabelece. Há ainda outro elemento que chama atenção, além da recorrência da ideia de ajuda e da ideia de presente que funcionam, como dito, como categorias opositivas à prostituição: a distância social que separa os sujeitos da relação. Além de uma diferença etária $e$ geracional entre eles, há um elemento de classe que, também nesse caso, mostra-se de forma sintomática.

$\mathrm{O}$ garoto com quem Mauro se envolvera, em determinado momento, pede uma volta de carro pela cidade. Não fica claro se esse jovem é um "garoto de programa" ou não, mas o fato é que 
o valor da transação era um passeio pela cidade. Talvez isso seja impensável em outros contextos. O jovem não conhecia a cidade e nunca tinha andado de carro por ela. Há aí, algumas pistas, quem sabe, das origens sociais distintas entre os sujeitos no "negócio".

Ainda assim, segundo o interlocutor, essa não seria a regra, já que ela consistiria em ele oferecer um algo mais para a efetivação da relação. Claramente, ele explica esta necessidade em vista de ser mais velho: "Eu tenho esse algo mais que falta para eles" [diz o interlocutor]. "Às vezes, isso é o dinheiro", completa. "Isso eles não têm. Mas eles têm a juventude, o corpo durinho, que eu não tenho. Daí a gente troca. Eu finjo que perco". Para ele, essa troca não é prostituição, porque a transação não é clara, ela é subliminar, ela está nas entrelinhas. Está na volta de carro, está no presente, no pagamento da conta no restaurante do centro da cidade, na passagem para a viagem até Corumbá. Não está na expressão: quanto custa o programa? Qual a duração? $O$ que é que você faz? Há outros elementos que tornam o processo um pouco mais complexo.

A categoria ajuda também apareceu nas conversas que tive com Rubens (66 anos), que é branco e pertence às camadas altas, um dos contatos que conheci pela internet. Quando era mais jovem, o interlocutor afirma que conseguia estabelecer uma relação de igual para igual. Rubens conta que, com o passar dos anos, tudo ficara diferente, pois para ainda ter os moleques, que são os que me atraem, eu preciso dispor de dinheiro ou outro tipo de ajuda. Meu interlocutor diz que tal situação, no começo, não foi confortável, pois ele recordava de como estabelecera os contatos e aproximações antes e via a situação se transformar de maneira drástica.

Tal como Mauro (67 anos), Rubens (66 anos) também entende que está diante de uma relação transacional na qual as partes trocam o que possuem e o que falta ao outro. $\mathrm{O}$ fato de encarar a relação com os moleques como uma troca não faria com que Rubens se sentisse explorado. Dons e dádivas que transitam 
nesse intercâmbio seriam, por um lado, corpo e juventude; e por outro, dinheiro ou outra forma de ajuda.

Com Tom (53 anos), que é branco e pertence às camadas médias, tive o diálogo que segue e que transcrevo porque parece sintomático para perceber as diferenciações que os sujeitos constroem para as experiências que tiveram em oposição ao que compreendem como prostituição.

E vocês dividiam as despesas?

Não, ele morava comigo lá em casa. Eu trabalhava e ele ficava dormindo.

Tu sempre bancou então?

Sempre.

E é comum isso: as pessoas mais velhas bancarem os namorados mais novos?

$\mathrm{Eu}$ acredito que sim. Eu acho que é hipocrisia um homossexual falar que não ajuda nenhum homem. É hipocrisia isso. Sempre. Todos ajudam.

Mas é mais neste sentido de ajuda?

Ajuda, não é prostituição. É de ajuda.

Mas e qual é a diferença?

A pessoa, o prostituto, o rapaz que vive disso ele não, eu acredito que, ele não te respeita. $\mathrm{E}$ quando existe esse relacionamento assim, existe um carinho. Uma coisa diferente.

Este bancar é prostituição?

Não é prostituição, é ajuda.

O que tu achas do sexo pago?

Eu nunca fiz isso.

Então, tu nunca contratou um garoto de programa? Não.

Mas nas tuas relações tu sempre ofereceste alguma coisa?

Sim. Sempre (Tom, 53 anos).

A prostituição, na concepção desses interlocutores, seria uma relação profissional que não envolveria o afeto. Tom fala na existência de respeito e carinho entre ele e o "companheiro bancado" como elemento diferenciador da prostituição; reforça a ideia da ajuda em contraposição à prostituição. Ele mostra não se 
perceber "pagando" por um serviço e que não teria problemas em bancar uma relação, desde que tivesse condições para tanto.

Trabalhar e dormir, categorias acionadas por ele para mostrar os lugares que o amante e que ele ocupam na relação, podem ser funções diferentes, mas complementares, que estruturam a relação estabelecida por eles. Seja no bancar, no agradar, ou no ajudar, há mais do que uma simples transa, há uma persistência do afeto, pelo menos na ótica dos interlocutores, pois o contato com os parceiros não termina com o "gozo" ou quando completa "a hora de serviço".

Os interlocutores mais velhos que se envolvem com os garotos podem estar tentando demonstrar que eles não têm apenas uma situação econômica mais favorável e que serviria de atrativo aos parceiros mais jovens, mas eles teriam também um saber mais elaborado sobre o que seria a "boa vida" e a ética nos relacionamentos. Nesse sentido, as convenções estabelecidas passariam pelas tentativas de mostrar que há mais a ser oferecido do que o dinheiro em troca de sexo. Para além da prostituição, o que o ajudar/bancar possibilita pensar reside no modo como as relações podem ser estabelecidas durante o processo de envelhecimento e na velhice.

\section{Sobre sexo, dinheiro e afeto}

Em contraposição ao bancar e a essa relação não declarada de transacionar sexo e desejo por algum ganho material, Deco preferiria a relação declarada de prostituição e o envolvimento eventual com um garoto de programa. Até porque, segundo ele:

Aí eu vou usar ele do jeito que eu quero. Eu vou fazer com ele tudo que eu quiser. Porque eu tô pagando. É diferente de eu bancar um cara, porque aí eu vou estar vivendo, eu vou estar envolvido emocionalmente com ele, com a pessoa. Com o garoto de programa eu não vou estar envolvido. É só sexo e pronto (Deco, 54 anos). 
Deco trata a relação com a prostituição como uma transação que envolve a compra e a venda de um produto $e$, por isso, segundo ele, quando tem dinheiro e disposição para tal, não sente qualquer culpa ou afetação moral por lançar mão desse serviço. É pro meu lazer, eu pago tranquilamente. Sem culpa nenhuma. Já paguei e não me arrependo. Muito pelo contrário. Foi muito bom.

Tatá (53 anos), que é pardo e pertence às camadas médias, argumenta no mesmo sentido. Ele vê a prostituição como uma relação de mais sinceridade diante do que ele chama de bancar ou prover. Para ele, desde que você tenha dinheiro pra pagar, eu acho que tudo é válido. O interlocutor encara a prostituição, inclusive, como uma relação mais barata, pois ele diz que em qualquer relação há gasto, há investimento. Às vezes, conclui Tatá, gastar apenas dinheiro é melhor do que gastar anos e anos da vida e depois ser traído ou abandonado. No entanto, alguns interlocutores preferem uma relação mais duradoura que envolveria ajudar/bancar o parceiro mais jovem.

Sobre a prostituição, Luma (57 anos) diz que se a contratação desse serviço vai me dar um pouco de prazer, na boa. É 20 reais, é 30 reais, pra pagar um lanche, pra gastar com a namorada. Ela diz que preferiria não precisar lançar mão disso, mas na falta de uma companhia estável, a prostituição é um recurso como outro qualquer. Ela reflete, por analogia, acerca da prostituição feminina: se é comum para o homem ir na zona $e$ fazer um programa com a menina e isso não interfere em nada, por que a gente não pode fazer da mesma forma? Por que pra gente é feio e nos diminui? Luma reivindica, para os usos da prostituição entre pessoas com conduta homossexual, um estatuto menos vexatório - o que, parece, ser o mais recorrente, inclusive entre os próprios usuários desse "negócio".

Outro dos interlocutores que admite contratar os serviços de garotos de programa é Mauro (67 anos) e não vê qualquer problema em lançar mão desse recurso. No entanto, sublinha que a prostituição é uma entre outras estratégias que estabelece para seus encontros eróticos e sexuais. Segundo ele, o sexo pago é 
ótimo. Acho muito sincero. Pagou, levou. Mauro relaciona o aumento do número de garotos de programa na cidade à falta dos antigos bofes que, hoje, ou estão com suas namoradas, que já os satisfazem, ou viraram bichas.

Os machos da região, Guilherme, são todos "made in China". Não tem mais homem de verdade como antigamente. Nem as bichas são bichas mesmo. Aquelas bichas legítimas, que eu chamo de "bichas havaianas". Estas morreram. Até eu morri já. Hoje está tudo mudado. Bicha já come bicha. Bicha come bofe. Bicha comendo. Vê se tem cabimento. Mas é assim que é e a gente se vira como pode. Os homens comem tanta mulher que quando encontram uma bicha, uma travesti, o que eles querem? Querem dar. Essa é a verdade. Homem quando sai com bicha e travesti sai pra dar. Eu como, sem problemas e com as bênçãos do Viagra (Mauro, 67 anos). ${ }^{14}$

Mauro parece testemunhar um tempo de transição que revelaria uma readequação na formação de pares e encontros eróticos e sexuais. Tempo cujas mudanças parecem evidentes ao interlocutor e faria dele velho, já que seu tempo era outro. Veja, aqui há o cruzamento entre uma temporalidade do mundo, em que os acontecimentos seguram uma espécie de lógica geral, $e$ uma temporalidade dos sujeitos, que - algumas vezes - não conseguiram acompanhar as transformações que operaram em uma temporalidade mais ampla, restando "desencontrados". Nessa articulação, o passado aparece como uma "ordem natural", em que a vida é interpretada a partir do presente como uma sequência coerente $e$ ordenada, $e$ o presente como um "apocalipse do gênero", já que tudo virou bagunça, especialmente no que diz respeito ao borramento dos lugares e das performances das pessoas com condutas homossexuais. Não haveria mais,

\footnotetext{
14 Sobre o medicamento Viagra, lançado em 1998 e conhecido como a pílula do sexo em alguns meios, bem como as transformações por ele operadas na vida sexual de homens mais velhos, é interessante a abordagem de Mauro Brigeiro (2000) em sua dissertação de mestrado.
} 
como antigamente, a ordenação da sexualidade a partir do gênero. ${ }^{15}$

Esse processo de mudança observado por Mauro não envolveria apenas a dinâmica das relações entre pessoas com conduta homossexual, senão também entre o que os interlocutores chamam de casais hetero. Teria operado transformações na região extinguindo o que o interlocutor chama de categorias legítimas e puras. bichas e machos. Segundo ele, esses sujeitos não existem mais. A dinâmica dos novos tempos teria criado os machos made in China e exterminado as bichas havaianas. Hoje, portanto, haveria apenas imitações das legítimas.

O passado de Mauro, e o de outros interlocutores, é marcado por uma experiência sintomática com a sexualidade. Quer dizer, nos limites do meu campo, a sexualidade pode ser vista como um marcador temporal. $\mathrm{E}$, mais que isso, não havia um ideal de conjugalidade aliado à experimentação da sexualidade. Isso é perceptível ao longo do trabalho: a ausência de relações afetivas. Os projetos de relações afetivas são escassos nas lembranças e na experiência de meus interlocutores. Além de não parecer viável, esse não parecia ser um investimento desejável. A questão parecia residir muito mais no erotismo e na sexualidade do que no campo da afetividade.

Uma possível explicação para isso poderia residir na persistência de um modelo hierárquico de relação, em grande medida no plano prático, mas, sobretudo, no plano ideal. Um projeto afetivo que envolve conjugalidade é devedor de um modelo mais igualitário e essa assertiva é, em muitos casos, impensada entre alguns de meus interlocutores. São, justamente, os desdobramentos desse modelo igualitário, que apagariam a figura do "homem hetero comedor de bicha" e os responsáveis pela bagunça de hoje em dia.

No entanto, como lembram alguns interlocutores, ainda hoje, seus parceiros sustentam, pelo menos de forma social, uma "heterossexualidade compulsória", ou seja, eles não se

${ }^{15}$ Agradeço ao antropólogo Sérgio Carrara por me fazer atentar a essas questões. 
compreendem como pessoas com conduta homossexual. Algumas vezes, como afirma Victor (54 anos), a necessidade faz com que os parceiros se submetam a performances que poderiam comprometer essa "heterossexualidade" pública. No entanto, pactos de segredo preservam as personas de ambos. Segundo Mauro (67 anos), por exemplo, seria mais fácil para o garoto ratificar sua conduta heterossexual, ao comer a bicha velha, porque para esses parceiros, a masculinidade do homem estaria preservada no ato de comer, independente de ser uma mulher ou uma bicha, tal como já fora observado por Peter Fry (1982).

A esse respeito, Rubens (66 anos) comenta que muitos dos garotos com quem saiu ou continua saindo, em Corumbá e na região, têm namoradas $e$, portanto, isso reafirmaria uma conduta heterossexual, pelo menos, de forma pública. Por outro lado, tal como Mauro, o interlocutor diz que poderia ser mais fácil para eles pensarem que são heteros saindo com homossexuais velhos para arrancar dinheiro. Em seguida, Rubens me lembra que ele é de uma geração em que as relações eram entre bichas e homens e a conduta heterossexual do homem não era posta em questão, pois era impensável que ele não fosse "heterossexual". Não tinha essa história de gay amigar com gay. Isso era impossível. Essa também é a queixa de Simone (67 anos), negra e pertencente às camadas populares, que acompanhou o processo de mudança que ocorreu no estabelecimento das relações e diz ainda preferir os homens.

Eu gosto de homem mesmo. Ah, homem mesmo na cama. Porque hoje em dia os homens, tá difícil de você pegar um homem. Eu gosto de homem mesmo. Eu gosto de heterossexual. Eu não sei, eu gosto da masculinidade dele. Hoje em dia você vê tudo as bicha tão amigada com outra (Simone, 67 anos).

Alguns interlocutores, em vista disso, não se adaptam de forma satisfatória às mudanças operadas atualmente. Eles vivem um tempo de desencontro, não raras vezes, de incompreensão dos rumos seguidos. Algo passível de aproximação foi percebido entre os "últimos homossexuais" de Ernesto Meccia (2011), diante dos 
avanços conquistados pela "gaycidade", com a inserção no mercado do consumo e do entretenimento, bem como com a visibilidade massificada necessária para a reivindicação de direitos. Reclamações de alguns interlocutores de Meccia têm eco no Pantanal, sobretudo quando meus contatos de campo mostram que teria acabado a graça, pois hoje não existiria mais o perigo do proibido, ou a dificuldade da conquista, afinal tudo se resolveria com meia dúzia de reais.

\section{Considerações finais}

Neste artigo, tentei mostrar que o processo de envelhecimento e a velhice também produzem uma tensão entre as dimensões de público e privado. Interessante notar que nos contextos em que eu trabalhei, as vivências da sexualidade são relacionadas com experiências públicas.

As tentativas de permanecer jovem, administrando a vivência de uma sexualidade com uma intensidade mais moderada, com mais cuidados, está ligada a uma ideia de trânsito e circulação pelo espaço público. Essa noção de público busca se contrapor ao privado, que é representado pelo "estar em casa" em frente à televisão, que seria próprio do "ser velho". Por que chamo a atenção para essa questão? Porque, costumeiramente, a sexualidade é alocada (com exceção do campo da prostituição) na dimensão privada. $\mathrm{O}$ meu campo mostra o contrário disso. A sexualidade está no público. ${ }^{16}$

Com esse intuito, problematizei as questões que envolvem sexualidade $e$ envelhecimento entre os interlocutores das diferentes redes. Para tanto, investi na ideia de como essas experiências foram se alterando com o passar do tempo. Apresentei ainda elementos que mostram como a sexualidade é

\footnotetext{
${ }^{16}$ A sexualidade como parte da dimensão pública também aparece nas pesquisas de Roberto Efrem Filho (2013). Em sua investigação, a exceção se dá entre as chamadas "bichas velhas", aquelas que contratam os "michês" e os levam para casa. Há, portanto, uma intersecção entre geração/envelhecimento com o privado que merece ser destacada.
} 
vivenciada pelos interlocutores no momento atual de suas vidas, bem com dialoguei com os processos de mudança que se operaram com o passar dos anos.

Procurei mostrar que o teorizado pela Gerontologia não necessariamente se faz presente no cotidiano dos meus interlocutores, que percebem o envelhecimento e a velhice como momentos de maior tranquilidade, exigindo algum retraimento social que acaba por gerar uma menor frequência sexual, quando não sua eliminação. Os interlocutores mais jovens, mesmo estes que ainda mantêm uma vida sexual ativa, já mostram os primeiros sinais de que o ritmo das investidas nesse universo está se tornando mais lento.

Mostrei como outro aspecto dessa dimensão do erotismo $e$ da intimidade, aliado à passagem dos anos, também passou por um processo de transformação. Falo especificamente dos amantes. Em um primeiro momento, ainda da juventude dos interlocutores, os amantes eram homens de verdade. As bichas havaianas, as legítimas, protagonizavam com eles os relacionamentos puros, nas farras e fervos de muito sexo hierárquico.

Hoje, estaria tudo mudado. Os machos seriam made in China, as legítimas bichas teriam sido extintas e o tempo atual se caracterizaria como bagunça, em que bicha amiga com bicha e os homens de verdade, as raridades, para se relacionar com as cinquentonas, ou com as veteranas, fariam-no, geralmente, apenas mediante agrados, ajudas e incentivos.

Nesse trânsito entre dons e dádivas, poderíamos, quem sabe, compreender algumas estratégias que fazem lembrar a "profissão mais antiga do mundo", cuja nova roupagem melindraria o moralmente, ainda reprovável, "uso tarifado do corpo" (Pocahy, 2012) para fins sexuais. Além disso, há nos discursos a busca por marcar diferença entre os processos por eles estabelecidos, sobretudo a ajuda, e a prostituição na tentativa de se manterem ativos no mercado erótico e sexual sem, necessariamente, se verem inseridos nesse fluxo ainda tão desprestigiado como recorrente: o comprar e vender momentâneo do corpo para fins sexuais. 
Nessas idas e vindas, como dizer que a realização plena da sexualidade das pessoas com condutas homossexuais só se efetivaria nos grandes centros urbanos? As páginas acima nos contam um pouco sobre o complexo processo de agência perpetrado pelos sujeitos para possibilitar a concretização de certa modalidade de afeto, erotismo e sexualidade que, nem sempre, caminha de mão dadas como a norma estabelecida.

Nesses processos de mudança que passeiam da "hierarquia à igualdade", em que, talvez, permaneça latente o desejo hierárquico, em contextos quase que impositivamente igualitários, a bicha precisou começar a comer, o macho, para desespero das legítimas, começou a dar e, entre uma volta de carro pela cidade, uma batedeira ou $\mathrm{R} \$ 20,00$, tornam-se possíveis os encontros intergeracionais nas calorosas noites do Pantanal de Mato Grosso do Sul.

\section{Referências bibliográficas}

ALvES, Andréa Moraes. A Dama e o Cavalheiro: um estudo antropológico sobre envelhecimento, gênero e sociabilidade. Rio de Janeiro, FGV, 2004.

ALVES, Marcelo. A gestão da experiência de envelhecer em um programa para a terceira idade: a Unati/Uerj. Textos Envelhecimento, vol. 2, $\mathrm{n}^{\circ}$ 2, 1999, pp.23-63.

BRIGEIRO, Mauro. Rir ou chorar? Envelhecimento, sexualidade e sociabilidade masculina. Dissertação (Mestrado em Saúde Coletiva), Instituto de Medicina Social, UERJ, Rio de Janeiro, 2000.

CASTElLS, Manuel. Sociedade em rede. São Paulo, Paz e Terra, 2000.

CORRÊA, Lúcia Salsa; CORRÊA, Valmir Batista. A história do Pantanal contada pelo MUHPAN. São Paulo, Via Impressa Edição de Artes, 2013.

DEBERT, Guita Grin. A construção e reconstrução da velhice: família, classe social e etnicidade. In: NERI, Anita Liberalesso; DEBERT, Guita Grin (orgs.). Velhice e Sociedade. Campinas-SP, Papirus, 1999, pp.41-68. 
DEBERT, Guita Grin; BRIGEIRO, Mauro. Fronteiras de gênero e a sexualidade na velhice. Revista Brasileira de Ciências Sociais, vol. 27, 2012, pp.37-54.

DeBert, Guita Grin; BrigeIRO, Mauro. A velhice, o sexo e o erotismo politicamente correto. In: PASSAMANI, Guilherme R. (org.). (Contra)pontos: ensaios de gênero, sexualidade e diversidade sexual. Cursos da vida e geraçôes. Campo Grande, Editora UFMS, 2013, pp.29-48,.

EFREM FILHO, Roberto. Corpos Brutalizados: conflitos e materializações nas mortes de LGBT. SPG15 - Sexualidade e gênero: espaço, corporalidades e relações de poder. $37^{\circ}$ Encontro Anual da ANPOCS, Águas de Lindóia-SP, 2013.

ERIBON, Didier. Reflexões sobre a questão gay. Rio de Janeiro, Companhia de Freud, 2008.

FEATHERSTONE, M. O curso da vida: corpo, cultura e o imaginário no processo de envelhecimento. In: DEBERT, G.G. (org). Antropologia e Velhice. Campinas-SP, IFCH/ UNICAMP, 1998, pp???.

FONSECA, Cláudia. A dupla carreira da mulher prostituta. Revista Estudos Feministas, n 1, 1996, pp.7-33.

FRY, P. Da hierarquia à igualdade: a construção histórica da homossexualidade no Brasil. In: FRY, Peter. Para inglês ver: identidade e política na cultura brasileira. Rio de Janeiro, Zahar, 1982, pp.87-115.

GORMAN-MURRAY, Andrew. Rethinking queer migration through the body. Social \& Cultural Geography, vol. 8, n 1, 2007, pp.105-121.

GREEN, James Naylor. Além do carnaval: a homossexualidade masculina no Brasil do século XX. São Paulo, EDUNESP, 2000.

GREGG, Jessica. He can be sad like that: Liberdade and the Absence of Romantic Love in a Brazilian Shantytown. In: HIRSCH, Jennifer; WARLOW, Holly. Modern Loves, The Anthropology of Romantic Courtship and companionate marriage. University of Michigan Press, 2006, pp.9-33.

GuIMARÃES, Carmen Dora. O homossexual visto por entendidos. Rio de Janeiro, Garamond, 2004. 
IACUB, Ricardo. La posgerontología: hacia un renovado estudio de la gerontología. Revista Latinoamericana de Psicología, vol. 34, n 1-2, 2002, pp.155-157.

IACUB, Ricardo. Erótica y vejez: perspectivas de Occidente. Buenos Aires, Paidós, 2011.

KATZ, Stephen; MARSHALL, Barbara. New sex for old: lifestyle, consumerism, and the ethics of aging well. Journal of Aging Studies, 17 (1), 2003, pp.3-16.

MeCcIA, Ernesto. Los últimos homosexuales. Sociología de la homosexualidad y la gaycidad. Buenos Aires, Gran Aldea Editores, 2011.

PISCITELli, A. Entre as máfias e a ajuda, a construção de conhecimento sobre tráfico de pessoas. cadernos pagu (31), Campinas-SP, Núcleo de Estudos de Gênero-Pagu/Unicamp, 2008, pp.29-63.

POCAHY, Fernando. Entre vapores \& vídeos pornôs: dissidências homo/eróticas na trama discursiva do envelhecimento masculino. Revista Estudos Feministas, Florianópolis-SC, Universidade Federal de Santa Catarina, vol. 20, n 2, 2012, pp.357-376.

SIMÕES, Julio Assis. Entre o lobby e as ruas: movimento de aposentados e politização da aposentadoria. Tese (Doutorado em Ciências Sociais), IFCH-PPGCS, Unicamp, Campinas, 2000.

. Homossexualidade masculina e curso da vida: pensando idades $e$ identidades sexuais. In: PISCITELLI, Adriana; GREGORI, Maria Filomena; CARRARA, Sérgio (orgs.). Sexualidade e saberes: convenções e fronteiras. Rio de Janeiro, Garamond, 2004, pp.415447.

SolivA, Thiago Barcelos. A confraria gay: um estudo de sociabilidade, homossexualidade e amizades na Turma OK. Dissertação (Mestrado em Sociologia e Antropologia), PPGSA, UFRJ, Rio de Janeiro, 2012.

WEEKS, Jeffrey. Os Problemas dos Homossexuais Mais Velhos. In: HART, John; RichaRDSON, Diane (orgs.). Teoria e Prática da Homossexualidade. Zahar Editores, Rio de Janeiro, 1983, PP. 236246. 
Weston, Kath. Get Thee to a Big City: Sexual Imaginary and the Great Gay Migration. GLQ: A Journal of Lesbian and Gay Studies, vol. 2, $\mathrm{n}^{\circ} 3,1995, \mathrm{pp} .253-277$. 